\title{
Mechanics and Computational Modelling of Pharmaceutical Tabletting Process
}

\author{
A. Baroutaji ${ }^{1,2}$, K. Bryan ${ }^{1}$, M. Sajjia ${ }^{3}$, S. Lenihan ${ }^{1}$ \\ ${ }^{1}$ Cork Institute of Technology, Cork, Ireland \\ ${ }^{2}$ University of Wolverhampton, Telford, United Kingdom \\ ${ }^{3}$ University of Limerick, Limerick, Ireland
}

\begin{abstract}
Tabletting is a cheap, but complicated, manufacturing process which is widely used in the pharma sector to produce pharmaceutical tablets as the most common form of solid dosage. The tabletting process is associated with many complex phenomena that may lead to undesirable tablet defects. Successful tabletting is very challenging and requires a sound knowledge of the powder behaviour during compaction.

For long time, experimental techniques have formed the base of development and troubleshooting in tabletting. In the recent years, computational modelling techniques have received increased attention to enhance the understanding of the process. Such techniques generate detailed information regarding the effect of many essential parameters such as tools shape, lubrication and compaction speed in a quick and cost-effective manner. Also, they offer access to results, such as internal stresses and density distribution, which cannot be obtained easily from the experimental data.

This chapter reviews the main research in the area of mechanics and modelling of pharmaceutical tabletting with a special focus on those techniques that can solve the technical problems in the process.
\end{abstract}

Keyword: Pharmaceutical powder compaction, finite element modelling, DPC model

\section{Introduction}

Powder compaction is widely used in pharma to produce pharmaceutical tablets and it is referred to as a tabletting process. Tabletting consists of three main stages: (1) die filling, where a mixture of pharmaceutical powders are delivered 
into the die cavity via a feed shoe; (2) compaction, where the powder is pressed inside a die by two punches to produce the tablet; and (3) ejection, where the tablet is ejected from the die by the lower punch. The powder behaviour during each of these stages has an effect on the properties of final tablet [1].

Despite wide adoption of tabletting process, obtaining a high-quality pharmaceutical compact continues to remain a significant challenge in practice as many complex interactions occur during the process and lead to many undesirable defects. Solving the main problems in tabletting necessitates a science-based approach that could help in establishing the comprehensive understanding of material behaviour and the failure causes. Due to complex and nonlinearity nature of the tabletting process, the tabletting problem cannot be solved analytically without major simplifications and thus empirical methods, such as Heckel analysis and Kawakita equation, have been used extensively to analyse the compaction process. However, the empirical techniques only consider the punch forces for assessing the tablet properties and cannot describe the main mechanisms of main tabletting issues. Recently, computational modelling has emerged as a powerful tool for attaining a new insight into the tabletting process. Computational modelling of the tabletting process is a very useful, effective and robustness technique that generates essential information about compact density, elastic deformation during ejection and the strength of the final product.

Moreover, tabletting process simulation can reduce material and development costs, enhance quality, and shorten time-to-market through virtual prototyping and optimisation. Also, the numerical simulations enable innovation through its unique numerical visualisation tools which offer a wealth of detailed information, not always readily available from experimental tests.

This chapter aims to present an overview of the main topics in the area of mechanics and computational modelling of pharmaceutical tabletting process. The focus of this chapter is on the finite element modelling approach as it is more suitable for solving the engineering problems of the tabletting process. 


\section{Compaction behaviour of pharmaceutical powder}

\subsection{Mechanics of powder compaction}

In general, several complicated mechanisms are associated with pharmaceutical tabletting processes such as rearrangement and densification of particles, inter-particles contact and friction, fragmentation and plastic deformation of particles. These mechanisms are not insulated and are difficult to analyse and predict [2].

shows the typical stress-strain curve during compaction of a typical pharmaceutical material (Microcrystalline cellulose (MCC)). During the compaction stage, represented by $\mathrm{AB}$ line, three complex densification mechanisms can be identified. Firstly, at the early stages of compaction, particle re-arrangement occurs due to translation and rotation movement of the particles. Upon contacting, the contact force between particles is mainly resolved into two components: tangential and normal forces, as shown in

Figure 2. The tangential component generates a moment, called a rolling moment, which contributes to particle rearrangement while the normal component of the contact force will take part in elastic-plastic deformation of the particles in the subsequent stages. In the second stage, elastic-plastic deformation occurs due to the contact interactions between the neighbouring particles leading to geometric hardening. If the compacted powder was brittle such as ceramic or lactose powders, crushing or fracturing of the particles occur instead of plastic deformation in this stage. Finally, the last steeper part of the curve, at the final stages of compaction, shows a sharp increase in the material flow resistance due to material strain hardening.

Once the compaction stage is completed, the upper punch is removed and the powder material attempts to revert to its initial state (i.e. before compaction) using the elastic properties. This stage is called as the unloading stage and is represented by BE line. During this stage, the material losses its stress and attempts to expand using some of the energy gained during the first stage, i.e. compaction stage. It can be seen that at the final stages of the unloading, segment DE, the powder exhibits nonlinear elastic behaviour due to the dilation behaviour of the pharmaceutical material [3].

\subsection{Compaction properties}

There are many mechanical properties that are important to understand the compaction behaviour of powders such as elasticity, plasticity, compactibility, 
and compressibility/flowability. Each property is represented by one or more mechanical parameters which in turn can be determined using various techniques. Compressibility means the ability of powder to undergo volume reduction under pressure and it is normally evaluated by Heckel equation which describes the mechanism of reducing volume during compaction as follows,

$$
\ln \left(\frac{1}{1-R D}\right)=K P+A
$$

Where $\mathrm{RD}$ is the relative density of the compact in a die at the compaction pressure P. It is clear that the Heckel equation assumes a linear relationship between $\ln \left(\frac{1}{1-\mathrm{RD}}\right)$ and $\mathrm{P}$ where $\mathrm{K}$ and $\mathrm{A}$ are the slope and intercept of the linear fitting of the curve, respectively. The reciprocal of the parameter $\mathrm{K}$ denotes yielding pressure $\left(\mathrm{P}_{\mathrm{Y}}\right)$ which represents the material ability to deform plastically under pressure. Also, $\mathrm{P}_{\mathrm{Y}}$ is an indicator of the material's compressibility where the lower $\mathrm{P}_{\mathrm{Y}}$ values indicate the onset of plastic deformation at lower pressures and thus better compressibility.

Elasticity is represented by Young's modulus (E) which can be calculated using standard techniques such as bending, indentation or instrumented compaction tests. Elasticity may also be expressed by elastic recovery (ER) parameter which is the ratio of tablet's axial expansion after ejection to the minimum thickness at the highest compaction pressure and it can be written as follows

$\operatorname{ER}(\%)=\frac{t-t_{\min }}{t_{\min }} \times 100$

Where $\mathrm{t}$ and $\mathrm{t}_{\min }$ are the thickness after ejection and under compression, respectively. $t_{\min }$ can be obtained from compression force versus displacement curve.

Compactibility is the ability of material to produce tablet with adequate mechanical strength. The mechanical strength of tablets is assessed by either axial or diametrical compression tests; the latter is most commonly used in pharma and it is expressed as hardness test. In general, compactibility can be evaluated using Leuenberger equation or by plotting the compression force versus tablet strength curves. Leuenberger equation describes the relation between the tensile strength (hardness) and the applied pressure as follows

$\sigma_{D}=\sigma_{\max }\left(1-e^{-R D \times P \times \gamma}\right)$ 
$\mathrm{RD}$ and $\mathrm{P}$ are the relative density and compression pressure respectively.

$\sigma_{\text {max }}$ denotes the theoretical maximum deformation hardness when the number of non-bonding points is reduced to zero and the applied compressive stress reaches highest or infinity. A low $\sigma_{\max }$ value shows relatively poor bonding properties and compactibility. The parameter $\gamma$ is compression susceptibility and demonstrates the rate at which the compact hardness $\sigma$ builds-up with an increase in applied compression stress. $\gamma$ parameter provides information about compressibility where higher values indicate better compressibility.

The other way to evaluate the compactiblity is by plotting the compression force versus tablet strength curves where the slope of this curve $(\mathrm{S})$ provides qualitative information about the ability of material to produce strong tablets. Higher values of $\mathrm{S}$ inferno better compactiblity. However, a very high value of $\mathrm{S}$ means a significant increase in the tablet crushing strength under a small change in the compression force which may lead to many problems in tabletting process [4].

Table 1 summarises the main compaction properties along with the representative parameters and extracting techniques.

\subsection{Compaction risks}

The most common defects which may happen during the tabletting process include sticking, chipping, capping and lamination, as shown in 
Figure 3. One of the main reasons for such failures is a non-homogenous density distribution which has wide ranging effects on the performance, quality and strength of the final tablet. The variation of density generates regions with high relative density surrounded by regions with low relative density, leading to inconsistent and local deformation and thus it could cause tablet failure. Regions with lower density are prone to damage during pre-tabletting processes such as coating or packaging and also offer faster dissolution rates when immersed in a liquid. The non-uniform density distribution is primarily caused by the frictional effects between the powdered material and compaction tools as well as friction between the particles themselves which induces non-uniform axial stresses and lead to density gradients inside the tablet. The frictional effects may also cause many other undesirable issues such as high compression and ejection forces, and wear of die wall [5].

In the practical tabletting process, the friction effects cannot be eliminated but it can be kept at minimal levels by using appropriate lubricants. Generally, two lubrication methods are used in pharmaceutical industry: (1) internal lubrication method where a lubricant, mostly magnesium stearate $(\mathrm{MgSt})$, is mixed with the pharmaceutical powders, and (2) external lubrication method which involves coating the lubricant on the die wall.

In summary, manufacture of high-quality tablet relies on the ability of the tabletting process in obtaining a uniform density distribution in the final tablet. This is significantly dependent on process parameters, such as the geometrical configuration of the tablet and tools and frictional conditions.

\subsection{Practical application of powder compaction in pharmaceutical industry}

Typically, the pharmaceutical tablet consists of active pharmaceutical ingredient (API) and excipients that serve several functions such as improve flowability, enhance compactibility, increase bulk volume, allow for swelling, assist in lubrication, colouring and flavouring [6]. The above components are mechanically mixed together to produce a uniform powder blend before the compaction. Following the mixing stage, the pharmaceutical powder mixture 
could be granulated before compaction in order to improve the flowability and compactibility properties and achieve a more uniform blend.

In general, granules provide obvious advantages over powders including high packing density, better flow behaviour, less dust formation, more regular shape and a controlled particle size distribution. Moreover, the granulation step allows avoiding many technological problems such as long-time consolidation or segregation of the bulk materials in bunkers and transporting containers [7].

The granulation of the pharmaceutical powder can be either wet or dry. The wet granulation can be performed by adding a liquid to the powder that binds the powder particles together. The mixture (i.e. powder and liquid) is dried and then milled to produce granules with desirable size distribution. Dry granulation can be performed by roller compacter where the powder is pressed between rollers to form a ribbon which is then milled to produce granules.

Once the granulation step is completed, the granules are delivered into a die to be compacted by the punches. Compaction is achieved through pressure applied by the punches. Many factors determine the amount of pressure that will be needed to compact the pharmaceutical powders, including the powder distribution in the die cavity and the lateral flow of the powder mixture.

The compaction machinery used in tabletting process could be either singlestation or rotary presses. The Rotary presses are normally used for high-volume production that can reach 1 million tablets per hour [5]. After compaction, the upper punch is removed and then the lower punch is pushed up to eject the tablet from the die. During the decompression and ejection stages of the tabletting process, the tablet dimensions are changed due to the elastic behaviour of the compacted powder. Controlling the elastic recovery is very important in the tabletting process because the main tablet failures may occur as a result of quick elastic recovery or spring back after compaction [1].

\section{Computational modelling of tabletting process}

\subsection{Modelling approaches}

The computational modelling of the powder compaction process can be performed by two approaches: micromechanical and macro-mechanical methods. 
In the micro-mechanical approach, also known as discrete element method (DEM), the discrete nature of the powder particles is considered by modelling each powder particle as a single object and analysing the inter-particle behaviour, such as the contact interaction and deformation of particles, by solving the equations of motion in Newton's second law. The powder behaviour in DEM approach is described by many parameters such as the average number of contacts, the volume fraction of particles, the orientation and distribution of contacts, the contact area and the length of the links connecting the particle centroids. DEM was originally developed by Cundall [8] for resolving soil mechanics problems. In the last two decades, DEM has been extensively used to simulate the behaviour of bulk materials in many applications such as flow behaviour and discharge [9], filling and packing [10], shearing behaviour [11], heap formation [12], bed configuration and loading conditions in fall mills [13], mixing and transportation [14], [15], and fluidised bed processes [16]. The application of DEM has been extended recently to model powder compaction [17], [18], [19] [20], [21] and [22] but it is still limited to powder compacts with low relative densities [23]. A very recent study [24] has established a promising approach which could be used to expand the application of DEM to compacts with high relative densities. However, the irregular shape and the large number of particles make using the DEM approach without incorporating some simplifications a very complicated process. Thus, a specific number of regular particles, mostly spherical, with well-established contact models have been considered by most of the researchers. In general, it was reported that the micromechanical approach is very useful for understanding the physical phenomena of the powder compaction process but it is not practical for modelling realistic problem as it cannot predict the global behaviour of the powder.

The macro-mechanical approach, or continuum approach, treats the powder as a continuous media and characterises the overall behaviour of the powder. The macro-mechanical approach is considered as a very reliable tool to simulate the powder compaction process since it is capable of generating essential information on the macroscopic behaviour of the powder, such as density and stress distributions, and the shape of compacted powders during and after the process. 
Such information is of great importance for solving technical problems in powder forming industry such as failure or fracture due to heterogeneous densification. The macroscopic modelling is performed by finite element method which requires a mathematical formulation derived from plasticity theory, called a constitutive model, to describe the elastic-plastic behaviour of the powder under compaction. In summary, it can be concluded that despite a powdered material is clearly discontinuous at the particle level, its compaction behaviour can be modelled using the principles of continuum mechanics which is more useful for engineering applications. Thus, since the macro-mechanical approach is more beneficial for addressing the technical problems in pharma, in-depth information on this modelling method is provided in the next section.

\subsection{Macro-mechanical modelling approach}

\subsubsection{Modelling requirements}

Establishing a finite element model of the tabletting process is a significant computational problem and requires a good knowledge of many parameters as follows: 1) The behaviour of powder material during the process which can mathematically be described by the material constitutive model, 2) The interaction between the powder and process tools (i.e. punches and die) which can be described by the friction constitutive model, 3) Geometrical configuration of the die and punches, 4) The movement procedure of the punches and velocity, 5) Initial state of the powder.

\subsubsection{Constitutive material model}

The constitutive model is the stress-strain mathematical relation of the material during all stages of the compaction process which should be incorporated in finite element code. The constitutive material model, adopted for powders under compaction, should be capable of representing all of physical complicated phenomena associated with the process, such as such as a very large reduction in volume, strain or work hardening, nonlinear densification, and the spring-back behaviour, in order to allow for more realistic and accurate numerical modelling. There are several constitutive material models which can mathematically represent the yield surfaces of powders such as Drucker-Prager Cap (DPC) model 
[25], the Cam-Clay model [26] and the DiMaggio-Sandler model [27]. All of these models were originally adopted from soil mechanics and were utilised to simulate the die compaction of metallic [28], ceramic [29] and recently pharmaceutical powders [2].

Among all of these models, the Drucker-Prager Cap (DPC) model [25] was the most adopted model in modelling the of pharmaceutical tablet [30], [31], [32], [33] and [3] and thus it would be described in detail in the following sections.

\subsubsection{Drucker-Prager Cap (DPC) model}

The DPC model is a pressure-dependant model which supposes that the behaviour of the powder is isotropic. Normally, the DPC model is represented in the hydrostatic pressure stress (p), Mises equivalent stress (q) coordinate system, as shown in Figure 4, by two main surfaces:

(1), the shear failure surface (Fs) which describe the main shear flow of the powder under low mean stresses and depends on the cohesion and the internal friction angle, as expressed in equation (4)

$F s(p, q)=q-p \tan \beta-d=o$

Where $\beta$ is the internal friction angle, $\mathrm{d}$ is the cohesion, $\mathrm{p}$ and $\mathrm{q}$ are the hydrostatic pressure and the Mises equivalent stresses, respectively.

In tablet compaction, $\mathrm{p}$ and $\mathrm{q}$ are given by equations (5), (6), respectively.

$$
\begin{aligned}
& p=-\frac{1}{3}\left(\sigma_{z}-\sigma_{r}\right) \\
& q=\left|\sigma_{z}-\sigma_{r}\right|
\end{aligned}
$$

Where $\sigma_{z}$ is axial stress, $\sigma_{r}$ is radial stress.

(2), the 'cap' surface Fc which depicts the strain-hardening plastic behaviour of the powder under high mean stresses induced during the compaction process. The FC surface is represented by an elliptical shape with a constant eccentricity, as shown in equation (7)

$$
\begin{gathered}
F c(p, q)=\sqrt{\left(p-p_{a}\right)^{2}+\left(\frac{R q}{l+\alpha-\frac{\alpha}{\cos \beta}}\right)^{2}}-R(d \\
\left.+p_{a} \tan \beta\right)=0
\end{gathered}
$$


Where $R$ is a cap shape parameter that controls the shape of the cap, $\alpha$ is a transition surface radius that takes a small value (typically $0.01-0.05$ ), and $\mathrm{p}_{\mathrm{a}}$ is an evolution parameter.

The transition surface $(\mathrm{Ft})$, the purple line in Figure 4, does not have any physical meaning. This surface, i.e. Ft, only used to allow for a smooth transition between the cap $(\mathrm{Fc})$ and the shear $(\mathrm{Ft})$ which is a numerical requirement to facilitate the application of FEM.

The Ft is mathematically expressed as in equation (8):

$F t(p, q)$

$=\sqrt{\left(p-p_{a}\right)^{2}+\left[q-\left(1-\frac{\alpha}{\cos \beta}\right) \times\left(d+p_{a} \tan \beta\right)\right]^{2}}$

$-\alpha\left(d+p_{a} \tan \beta\right)=o$

The full description of DPC model requires knowledge of flow rule. The DPC model uses an associated flow potential $\left(\mathrm{G}_{\mathrm{c}}\right)$ for the cap region and non-associated flow potential (Gs) for the shear line and transition segment. The Gc and Gs flow potentials are expressed as follows in equations (9) and (10)

$G_{c}=\sqrt{\left(p-p_{a}\right)^{2}+\left[\frac{R q}{l+\alpha-\frac{\alpha}{\cos \beta}}\right]^{2}}$

$G_{s}=\sqrt{\left[\left(p_{a}-p\right) \tan \beta\right]^{2}+\left[\frac{q}{l+\alpha-\frac{\alpha}{\cos \beta}}\right]^{2}}$

Since the powders exhibit a strain hardening behaviour during the compaction where the volume reduces and the material becomes harder, DPC uses a hardening rule to define the dependence of hydrostatic compression yield stress $\left(\mathrm{p}_{\mathrm{b}}\right)$ on volumetric plastic strain $\left(\varepsilon_{\mathrm{v}}^{\mathrm{p}}\right)$, as shown in equation (11):

$p_{b}=\mathrm{f}\left(\varepsilon_{v}^{p}\right)$

The volumetric plastic strain is given by equation (12)

$\varepsilon_{v}^{p}=\ln (R D / R D o)$

Where $R D$ and $R D_{o}$ are the final and initial relative densities, respectively. 
The last powder behaviour which should be included in the constitutive model is elasticity. Considering of the elastic behaviour is of critical importance for successful modelling of the tablet compaction process particularly during decompaction and ejection stages where most strains are elastic.

Experimental investigations on the pharmaceutical powders have revealed that powders offered nonlinear elastic behaviour during unloading phase of the compaction process because of the powder dilation phenomena.

The elastic properties of the powder can be expressed by Young's modulus (E) and the Poisson's ratio (v). A nonlinear elasticity law should be used to calculate the elastic properties which should be independent of the stress path to avoid hysteresis.

\subsubsection{DPC Model Calibration}

Calibration of DPC model means determination of model parameters, i.e. $d, \beta, R$, $\mathrm{P}_{\mathrm{b}}, \mathrm{P}_{\mathrm{a}}, \mathrm{E}$ and $v$, which can be used in finite element code.

One of the most important features of the DPC model is that it can be easily calibrated by performing a limited number of experiments on powders [34], [28], [2] and [1]. For pharmaceutical powder, DPC parameters can be calculated using a previously published approach [30], [35], [36] which involve using of an instrumented die equipment. Table 2 summarises the main experiments required for calculating DPC parameters.

The cohesion and internal friction angle can be obtained by conducting diametrical compression and uniaxial compression.

From the diametrical compression test, the diametrical strength $\left(\sigma_{\mathrm{D}}\right)$, also known as tensile strength, can be determined using equation (13)

$$
\sigma_{\mathrm{D}}=\frac{2 \mathrm{~F}_{\mathrm{D}}}{\pi \mathrm{Dt}}
$$

Where FD is the maximum crush force, $\mathrm{D}$ and $\mathrm{t}$ are the diameter of and thickness of the tablet, respectively.

The uniaxial compression test allows for calculating the uniaxial strength as follows 
$\sigma_{\mathrm{c}}=\frac{4 \mathrm{~F}_{\mathrm{c}}}{\pi \mathrm{D}^{2}}$

Where Fc is the uniaxial breaking force, $\mathrm{D}$ is the diameter of the tablet.

Subsequently, after calculating the uniaxial and diametrical strength, the cohesion

(d) and internal friction angle can be calculated as follows

$\mathrm{d}=\frac{\sigma_{\mathrm{c}} \sigma_{\mathrm{D}}(\sqrt{13}-2)}{\sigma_{\mathrm{c}}+2 \sigma_{\mathrm{D}}}$

$\beta=\tan ^{-1}\left\lfloor\frac{3\left(\sigma_{\mathrm{c}}+\mathrm{d}\right)}{\sigma_{\mathrm{c}}}\right\rfloor$

An instrumented die compaction test is normally used to deduce the cap line parameters, i.e. $p_{\mathrm{a}}$ and $\mathrm{R}$. The stress state $\left(\mathrm{p}_{\mathrm{B}}, \mathrm{q}_{\mathrm{B}}\right)$ at maximum compaction, Point $\mathrm{B}$ in Figure 1, is calculated in terms of radial and axial pressure as follows

$$
\begin{aligned}
& \mathrm{p}_{\mathrm{B}}=\frac{1}{3}\left(\sigma_{\mathrm{z}}+2 \sigma_{\mathrm{r}}\right) \\
& \mathrm{q}_{\mathrm{B}}=\left|\sigma_{\mathrm{z}}-\sigma_{\mathrm{r}}\right|
\end{aligned}
$$

Where $\sigma_{\mathrm{z}}$ is axial stress, $\sigma_{\mathrm{r}}$ is radial stress.

The $\mathrm{Pa}$ and $\mathrm{R}$ are defined as follows

$\mathrm{p}_{\mathrm{a}}$

$=-\frac{\left[3 \mathrm{q}_{\mathrm{B}}+4 \mathrm{~d} \tan \beta(1+\alpha-\alpha / \cos \beta)^{2}\right]}{4\left[(1+\alpha-\alpha / \cos \beta)^{2}\right]}$

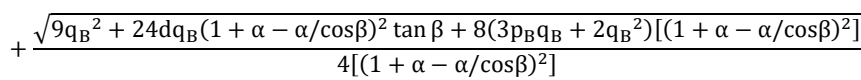

$R=\sqrt{\frac{2(1+\alpha-\alpha / \cos \beta)^{2}}{3 q_{B}}\left(p_{B}-p_{a}\right)}$

The parameter $\alpha$ is a small value (typically 0.01-0.05) [30], [35].

Lastly, the $\mathrm{p}_{\mathrm{b}}$ can be determined as follows

$\mathrm{p}_{\mathrm{b}}=\mathrm{p}_{\mathrm{a}}+\mathrm{R}\left(\mathrm{d}+\mathrm{p}_{\mathrm{a}} \tan \beta\right)$

The elastic parameters, The Young's modulus (E) and Poisson's ratio (v), are calculated from the unloading curve of the instrumented die compaction test as follows in equations (22) and (23)

$\vartheta=\frac{\frac{d \sigma_{r r}}{d \sigma_{z z}}}{1+\frac{d \sigma_{r r}}{d \sigma_{z z}}}$ 
$\mathrm{E}=\frac{d \sigma_{z z}}{d \varepsilon_{z z}} \frac{(1+\vartheta)(1+2 \vartheta)}{1-\vartheta}$

$\mathrm{d} \sigma_{\mathrm{rr}}$ is the normal radial stress increment during unloading, $\mathrm{d} \sigma_{\mathrm{zz}}$ is axial strain increment during unloading, and $\mathrm{d} \varepsilon_{z z}$ is the axial strain increment during unloading. Calculating $\frac{d \sigma_{z z}}{d \varepsilon_{z z}}$ and $\frac{d \sigma_{r r}}{d \sigma_{z z}}$ ratios is somewhat difficult due to fact that the unloading curves for most powders are non-linear; an approach of obtaining these ratios can be found in [37].

For modelling of tabletting, DPC model's parameters should be calculated as a function of the relative density to take into account the changes in powder's properties during the process. The relative density is defined as the ratio of tablet density to the true density of the powder.

\subsubsection{Modelling of Frictions in tabletting process}

The friction between the powders and die wall is normally expressed by friction coefficient. The accurate determination of friction coefficient is very important for the successful modelling of powder compaction.

Measuring wall friction can be performed by compacting the powder in an instrumented die which has a radial pressure sensor. Based on Janssen-Walker theory, the friction coefficient can be calculated as in equation (24)

$\mu=\frac{D}{4 h} \frac{\sigma_{\text {Bottom }}}{\sigma_{r}}\left(\frac{\sigma_{\text {Top }}}{\sigma_{\text {Bottom }}}\right)^{\frac{z}{h}} \ln \left(\frac{\sigma_{\text {Top }}}{\sigma_{\text {Bottom }}}\right)$

Where $\mathrm{D}$ is the die interior diameter, $\mathrm{H}$ is the compaction height in the die, $\sigma_{\mathrm{r}}$ is the radial pressure at the position $\mathrm{z}$ from the top surface of the powder, and $\sigma_{\mathrm{B}}$ and $\sigma_{\mathrm{T}}$ are axial compression stresses applied by the upper and lower punches, respectively.

Once the friction coefficient is determined, it can be incorporated in the finite element code for representing the friction during compaction.

\subsubsection{Modelling applications}

Michrafy [2], Sinka [38] and Cunningham [35] were among the first who verified the validity of the finite element modelling for tablet compaction.

Typically, the finite element modelling of tabletting process can be used to: 
- Estimate and analyse the stress and density distributions within the tablet where these distributions may influence the mechanical properties, dissolution, drug release, and the potential damage during coating, and transport [30].

- Investigate the effect of punch shape and optimise the compaction tools [33] and [3].

- Explore the tablet failure mechanism and assess the origin of defect or crack formation [1], [33], [39], [31], [40] and [41].

- Estimate the break force of the tablet which can replace the empirical methods currently used in design and development process of pharmaceutical product [32].

- Estimate the temperature evolution during compaction that has a direct effect on compressibility and strength, lubricant efficiency, friction between tools, and ejection force [31], [42].

- Investigate the effect of interaction (i.e. friction) between the powder and compaction tools on the process and tablet structure [38].

\section{Conclusion}

This chapter provides an overview on development, usage and importance of computational models for pharmaceutical powder compaction. Tabletting of pharmaceutical powder is a complicated manufacturing process which involves a transformation from a loose powder state to a solid tablet. Exploring the effect of various variables in powder compaction process experimentally is a very expensive and time-consuming procedure and thus the computational modelling of tabletting has emerged as a proper solution for effective development of the process. The computational modelling techniques, particularly FEM, facilitates the design and optimisation of the process, enable systematic simulation, eliminate the need for building a prototype of the system, accelerate the development process and reduce the costs. Finite element models of the tabletting process have been developed over the time and have been successfully used to predict the density and stress maps within the tablet, optimise the geometry of the tooling, establish the mechanism of tablet defects, and so on. However, developing a finite element model of the tabletting process is not easy and 
requires a profound combined knowledge of related topics such as compaction mechanics, bulk material science, theory of plasticity and computational modelling background.

\section{Acknowledgment}

The project fund is provided by the Pharmaceutical Manufacturing Technology Centre (PMTC) in Ireland.

\section{Reference}

[1] C. Y. Wu, O. M. Ruddy, a. C. Bentham, B. C. Hancock, S. M. Best, and J. a. Elliott, "Modelling the mechanical behaviour of pharmaceutical powders during compaction," Powder Technol., vol. 152, no. 1-3, pp. 107-117, 2005.

[2] a. Michrafy, D. Ringenbacher, and P. Tchoreloff, "Modelling the compaction behaviour of powders: Application to pharmaceutical powders," Powder Technol., vol. 127, no. 3, pp. 257-266, 2002.

[3] A. Krok, M. Peciar, and R. Fekete, "Numerical investigation into the influence of the punch shape on the mechanical behavior of pharmaceutical powders during compaction," Particuology, vol. 16, pp. 116-131, Oct. 2014.

[4] S. Jain, "Mechanical properties of powders for compaction and tableting: an overview," Pharm. Sci. Technolo. Today, vol. 2, no. 1, pp. 20-31, 1999.

[5] I. Sinka, "Modelling Powder Compaction," Knowl. Creat. Diffus. Util., vol. 25, no. 25, pp. 4-22, 2007.

[6] P. Brewin, O. Coube, and P. Doremus, Modelling of powder die compaction. 2008.

[7] S. Antonyuk, S. Heinrich, J. Tomas, N. G. Deen, M. S. van Buijtenen, and J. A. M. Kuipers, "Energy absorption during compression and impact of dry elastic-plastic spherical granules," Granul. Matter, vol. 12, no. 1, pp. 15-47, Jan. 2010.

[8] P. A. Cundall and O. D. L. Strack, "A discrete numerical model for granular assemblies," Géotechnique, vol. 29, no. 1, pp. 47-65, Jan. 1979.

[9] R. Balevičius, R. Kačianauskas, Z. Mroz, and I. Sielamowicz, "Discrete element method applied to multiobjective optimization of discharge flow parameters in hoppers," Struct. Multidiscip. Optim., vol. 31, no. 3, pp. 163-175, Jan. 2006.

[10] Z. . Zhang, L. . Liu, Y. . Yuan, and A. . Yu, "A simulation study of the effects of dynamic variables on the packing of spheres," Powder Technol., vol. 116, no. 1, pp. 23-32, May 2001. 
[11] R. Tykhoniuk, J. Tomas, S. Luding, M. Kappl, L. Heim, and H.-J. Butt, "Ultrafine cohesive powders: From interparticle contacts to continuum behaviour," Chem. Eng. Sci., vol. 62, no. 11, pp. 2843-2864, Jun. 2007.

[12] H. G. Matuttis, S. Luding, and H. J. Herrmann, "Discrete element simulations of dense packings and heaps made of spherical and nonspherical particles," Powder Technol., vol. 109, no. 1-3, pp. 278-292, Apr. 2000.

[13] R. Venugopal and R. . Rajamani, "3D simulation of charge motion in tumbling mills by the discrete element method," Powder Technol., vol. 115, no. 2, pp. 157-166, Apr. 2001.

[14] J. Gyenis, Z. Ulbert, J. Szépvölgyi, and Y. Tsuji, "Discrete particle simulation of flow regimes in bulk solids mixing and conveying," Powder Technol., vol. 104, no. 3, pp. 248-257, Oct. 1999.

[15] M. Kwapinska, G. Saage, and E. Tsotsas, "Mixing of particles in rotary drums: A comparison of discrete element simulations with experimental results and penetration models for thermal processes," Powder Technol., vol. 161, no. 1, pp. 69-78, Jan. 2006.

[16] J. M. Link, L. A. Cuypers, N. G. Deen, and J. A. M. Kuipers, "Flow regimes in a spout-fluid bed: A combined experimental and simulation study," Chem. Eng. Sci., vol. 60, no. 13, pp. 3425-3442, Jul. 2005.

[17] A. Samimi, A. Hassanpour, and M. Ghadiri, "Single and bulk compressions of soft granules: Experimental study and DEM evaluation," Chem. Eng. Sci., vol. 60, no. 14, pp. 3993-4004, Jul. 2005.

[18] O. Skrinjar and P.-L. Larsson, "Cold compaction of composite powders with size ratio," Acta Mater., vol. 52, no. 7, pp. 1871-1884, Apr. 2004.

[19] O. Skrinjar and P.-L. Larsson, "On discrete element modelling of compaction of powders with size ratio," Comput. Mater. Sci., vol. 31, no. 1-2, pp. 131-146, Sep. 2004.

[20] O. Skrinjar and P.-L. Larsson, "On the local contact behaviour in regular lattices of composite powders," J. Mater. Process. Technol., vol. 184, no. 1-3, pp. 312-318, Apr. 2007.

[21] E. Olsson and P.-L. Larsson, "A numerical analysis of cold powder compaction based on micromechanical experiments," Powder Technol., vol. 243, pp. 71-78, Jul. 2013.

[22] E. Olsson and P.-L. Larsson, "On the Effect of Particle Size Distribution in Cold Powder Compaction," J. Appl. Mech., vol. 79, no. 5, p. 51017, Sep. 2012.

[23] P. Redanz and N. A. Fleck, "The compaction of a random distribution of metal cylinders by the discrete element method," Acta Mater., vol. 49, no. 20, pp. 4325-4335, Dec. 2001.

[24] C. Tsigginos, J. Strong, and A. Zavaliangos, "On the force-displacement law of contacts between spheres pressed to high relative densities," Int. J. Solids Struct., vol. 60-61, pp. 17-27, May 2015. 
[25] D. Drucker and W. Prager, "Soil mechanics and plastic analysis or limit design," Q. Appl. Math., vol. 10, pp. 157-165, 1952.

[26] A. N. Schofield and C. P. Wroth, Critical State Soil Mechanics. London: McGraw-Hill, 1968.

[27] F. L. DiMaggio and I. S. Sandler, "Material Model for Granular Soils," J. Eng. Mech. Div., vol. 97, no. 3, pp. 935-950, 1970.

[28] O. Coube and H. Riedel, "Numerical simulation of metal powder die compaction with special consideration of cracking," Powder Metall., vol. 43, no. 2, pp. 123-131, Feb. 2000.

[29] İ. Aydin, B. J. Briscoe, and K. Y. Şanlitürk, "The internal form of compacted ceramic components: a comparison of a finite element modelling with experiment," Powder Technol., vol. 89, no. 3, pp. 239254, Dec. 1996.

[30] L. H. Han, J. a. Elliott, a. C. Bentham, A. Mills, G. E. Amidon, and B. C. Hancock, "A modified Drucker-Prager Cap model for die compaction simulation of pharmaceutical powders," Int. J. Solids Struct., vol. 45, no. 10, pp. 3088-3106, 2008.

[31] G. R. Klinzing, A. Zavaliangos, J. Cunningham, T. Mascaro, and D. Winstead, "Temperature and density evolution during compaction of a capsule shaped tablet," Comput. Chem. Eng., vol. 34, no. 7, pp. 10821091, 2010.

[32] C. Shang, I. C. Sinka, and J. Pan, "Modelling of the break force of tablets under diametrical compression," Int. J. Pharm., vol. 445, no. 1-2, pp. 99107, 2013.

[33] M. S. Kadiri and A. Michrafy, "The effect of punch's shape on die compaction of pharmaceutical powders," Powder Technol., vol. 239, pp. 467-477, 2013.

[34] I. Aydin, B. J. Briscoe, and N. Ozkan, "Modeling of Powder Compaction: A Review," MRS Bull., vol. 22, no. 12, pp. 45-51, Nov. 2013.

[35] J. C. Cunningham, I. C. Sinka, and A. Zavaliangos, "Analysis of tablet compaction. I. Characterization of mechanical behavior of powder and powder/tooling friction," J. Pharm. Sci., vol. 93, no. 8, pp. 2022-2039, 2004.

[36] C. Shang, I. C. Sinka, and J. Pan, "Constitutive Model Calibration for Powder Compaction Using Instrumented Die Testing," Exp. Mech., vol. 52, no. 7, pp. 903-916, 2012.

[37] K. LaMarche, D. Buckley, R. Hartley, F. Qian, and S. Badawy, "Assessing materials' tablet compaction properties using the DruckerPrager Cap model," Powder Technol., vol. 267, pp. 208-220, 2014.

[38] I. C. Sinka, J. C. Cunningham, and A. Zavaliangos, "The effect of wall friction in the compaction of pharmaceutical tablets with curved faces: A validation study of the Drucker-Prager Cap model," Powder Technol., vol. 133, no. 1-3, pp. 33-43, 2003. 
[39] C. Y. Wu, B. C. Hancock, A. Mills, a. C. Bentham, S. M. Best, and J. a. Elliott, "Numerical and experimental investigation of capping mechanisms during pharmaceutical tablet compaction," Powder Technol., vol. 181, no. 2, pp. 121-129, 2008.

[40] S. Garner, E. Ruiz, J. Strong, and A. Zavaliangos, "Mechanisms of crack formation in die compacted powders during unloading and ejection: An experimental and modeling comparison between standard straight and tapered dies," Powder Technol., vol. 264, pp. 114-127, 2014.

[41] R. Furukawa, Y. Chen, A. Horiguchi, K. Takagaki, J. Nishi, A. Konishi, Y. Shirakawa, M. Sugimoto, and S. Narisawa, "Numerical evaluation of the capping tendency of microcrystalline cellulose tablets during a diametrical compression test," Int. J. Pharm., vol. 493, no. 1, pp. 182-191, 2015.

[42] A. Krok, P. García-Triñanes, M. Peciar, and C.-Y. Wu, "Finite element analysis of thermomechanical behaviour of powders during tabletting," Chem. Eng. Res. Des., vol. 110, pp. 141-151, 2016.

[43] K. H. Lee, J. M. Lee, and B. M. Kim, "Densification simulation of compacted Al powders using multi-particle finite element method," Trans. Nonferrous Met. Soc. China (English Ed., vol. 19, no. SUPPL. 1, pp. s68s75, 2009. 
Figure 1: Typical axial stress $\left(\sigma_{\mathrm{z}}\right)$-axial strain $\left(\varepsilon_{\mathrm{z}}\right)$ curve during compaction of pharmaceutical powder [3].

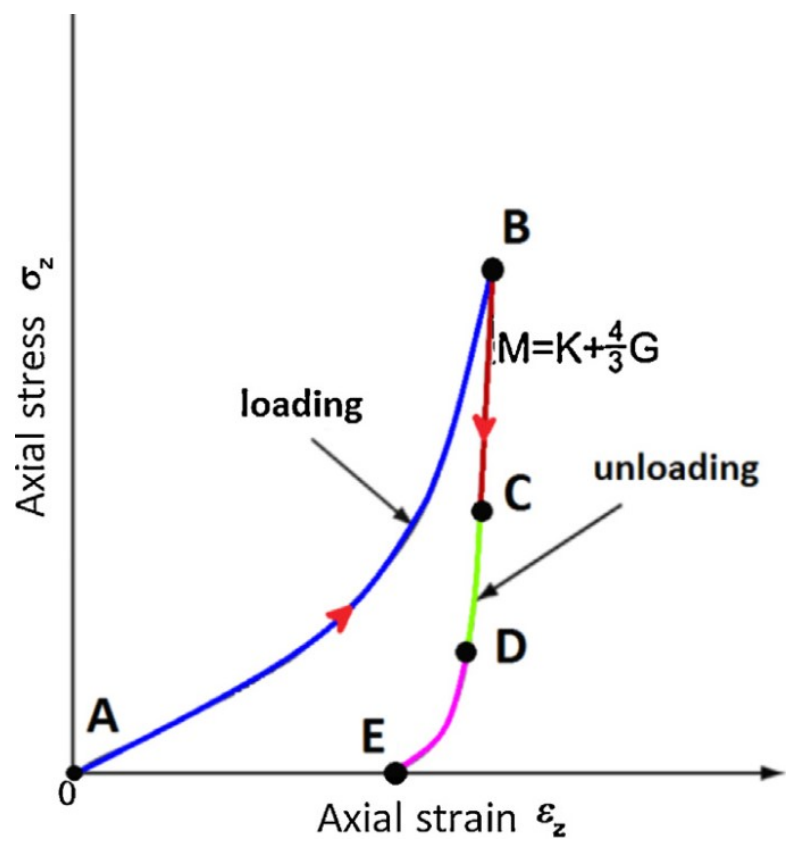


Figure 2: Stages of powder compaction [43]

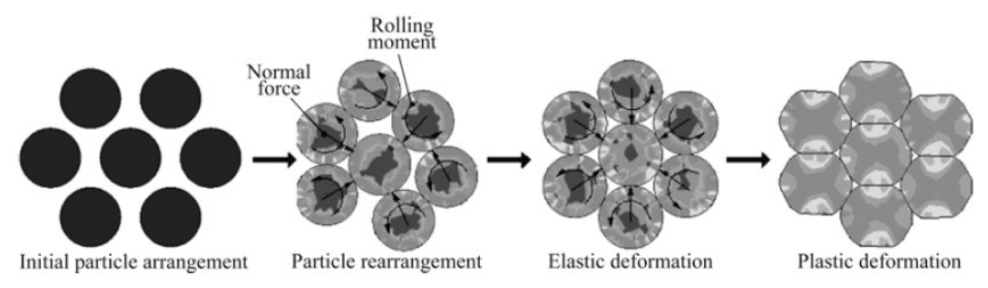


Figure 3: Common tablet defects (a) chipping (b) lamination (c) capping

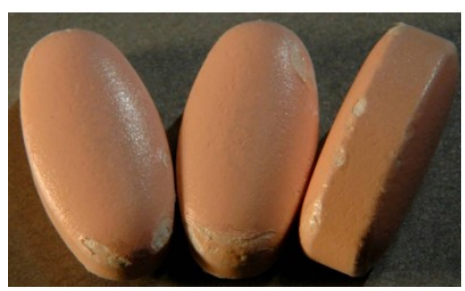

(a)

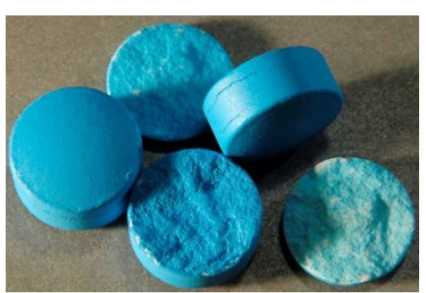

(b)

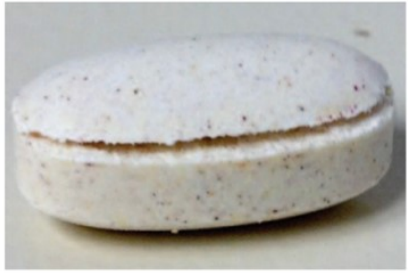

(c) 
Figure 4: Drucker-Prager Cap material model

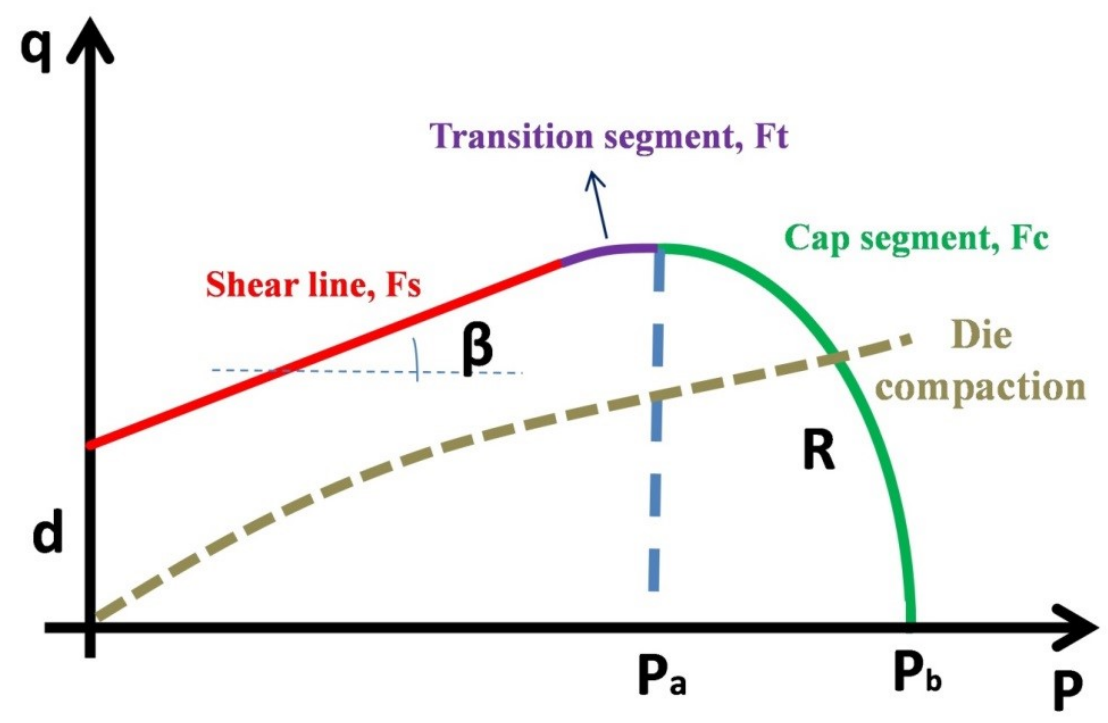


Table 1: Summary of compaction properties

\begin{tabular}{|l|c|l|}
\hline $\begin{array}{l}\text { Compaction } \\
\text { Property }\end{array}$ & $\begin{array}{l}\text { Representative } \\
\text { parameter }\end{array}$ & Testing Technique \\
\hline \multirow{2}{*}{ Elasticity } & $\mathrm{E}$ & $\bullet \quad$ Beam bending \\
& & $\begin{array}{l}\text { Indentation testing } \\
\text { Instrumented die } \\
\text { compaction test }\end{array}$ \\
\cline { 2 - 3 } & $\mathrm{ER} \%$ & $\begin{array}{l}\text { Force versus displacement } \\
\text { curves during compaction }\end{array}$ \\
\hline Plasticity & $\mathrm{P}_{\mathrm{Y}}$ & Heckel Equation \\
\hline Tablet strength & $\sigma_{D}$ & Diametrical compression test \\
\cline { 2 - 4 } & $\sigma_{\mathrm{c}}$ & Uniaxial compressive strength \\
\hline Compactibility & $\mathrm{S}$ & $\begin{array}{l}\text { Compression force versus tablet } \\
\text { strength }\end{array}$ \\
\hline Compressibility & $\mathrm{P}_{\mathrm{Y}}$ & Leuenberger equation \\
\hline & $\gamma$ & Leuenberger equation \\
\hline
\end{tabular}


Table 2: Experimental procedure for calibrating DPC model

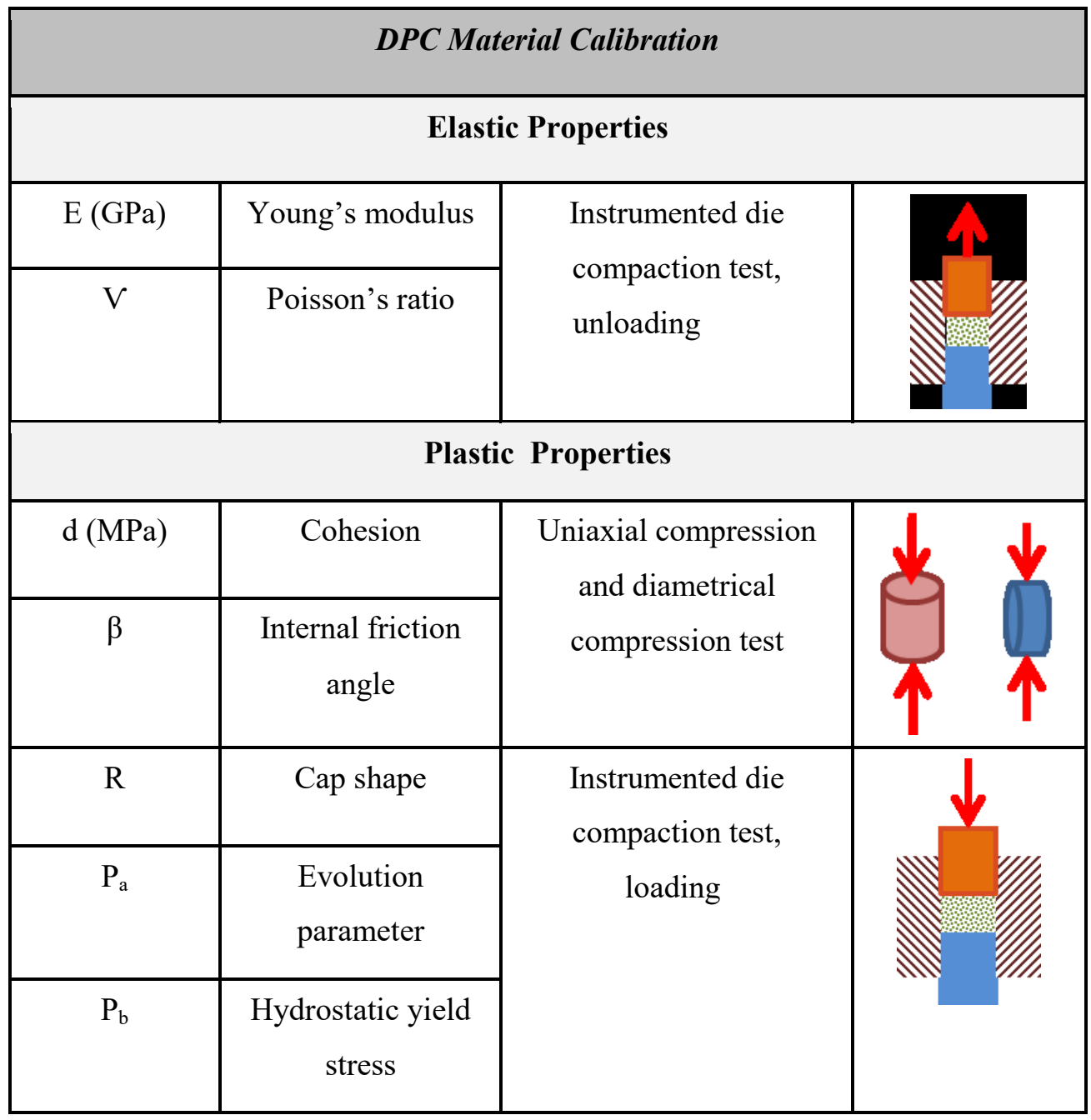

